\title{
Prevalence of Lewis Blood Group Polymorphisms in Southern Thai Blood Donors
}

\author{
Natthaphon Nanakorn, Ph.D. ${ }^{1}$, Suwimon Boonthongkhao, M.Sc. ${ }^{2}$, Supattra Mitundee, M.Sc. ${ }^{3}$ \\ Natda Tonwong, Ph.D. ${ }^{1}$
}

${ }^{1}$ Faculty of Medical Technology, Prince of Songkla University, Hat Yai, Songkhla 90110, Thailand.

${ }^{2}$ Department of Pathology, Faculty of Medicine, Prince of Songkla University, Hat Yai, Songkhla 90110, Thailand.

${ }^{3}$ Regional Blood Centre XII, Songkhla, Thai Red Cross Society, Hat Yai, Songkhla 90110, Thailand.

Received 27 May 2021 • Revised 26 August 2021 • Accepted 9 September 2021 • Published online 25 October 2021

\section{Abstract:}

Objective: To determine the frequencies of five of the most common (59T>G, 202T>C, 314C>T, 508G>A and 1067T>G) single nucleotide polymorphisms (SNPs) of the FUT3 gene in Thai blood donors and examine their associations with the presence or absence of Lewis antigens on red blood cells.

Material and Methods: A total of 364 donor specimens from Songklanagarind Hospital and Regional Blood Centre XII Songkhla, Thailand, were recruited for the study. Molecular analysis of each SNP was performed by polymerase chain reaction amplification with sequence-specific primers (PCR-SSP). The Lewis phenotype was investigated in 159 individuals using the standard hemagglutination test.

Results: The frequencies of the SNPs were 32.0\% (59T>G), 46.6\% (202T>C), 21.7\% (314C>T), 37.9\% (508G>A), and $25.0 \%(1067 \mathrm{~T}>\mathrm{A})$. The prevalences of the Lewis phenotype were $61.0 \%$ for Le(a-b+), 7.6\% for Le $(a+b-), 11.3 \%$ for Le $(a+b+)$, and $20.1 \%$ for Le(a-b-). The Lewis-negative phenotype was significantly associated with homozygosity in 59T $>\mathrm{G}$ and 1067T $>\mathrm{A}\left(\chi^{2}=49.873\right.$, and $\chi^{2}=44.520$, respectively $)$.

Conclusion: Our findings suggest that $l e^{59,1067}$ is largely responsible for the Lewis-negative phenotype in our southern Thai population. Genetic variations in FUT3 polymorphisms may be used as molecular markers for ethnicity and to help understand the roles of the Lewis blood group in infections or clinical diseases.

Keywords: Lewis blood group, FUT3 gene, polymorphisms, PCR-SSP

Contact: Natda Tonwong, Ph.D.

Faculty of Medical Technology, Prince of Songkla University, Songkhla 90110, Thailand.

E-mail: natda.t@psu.ac.th

๑ 2021 JHSMR. Hosting by Prince of Songkla University. All rights reserved.

This is an open access article under the CC BY-NC-ND license

(http://www.jhsmr.org/index.php/jhsmr/about/editorialPolicies\#openAccessPolicy).
J Health Sci Med Res 2022;40(4):391-400 doi: 10.31584/jhsmr.2021847 www.jhsmr.org 


\section{Introduction}

Lewis blood group antigens are thought to be primarily synthesized in epithelial cells in digestive organs and presented in secretions such as plasma, and then adsorbed onto red blood cells. Expression of the two major antigens, $L e^{a}$ and $L e^{b}$, is involved with the interaction of two fucosyltransferase enzymes, $\alpha(1,2)$-fucosyltransferase (FUT2) and $\alpha(1,3 / 1,4)$-fucosyltransferase (FUT3). The FUT3 (also called the Lewis enzyme) transfers fucose to the subterminal $N$-acetylglucosamine (GlcNAc) on the type 1 and $H$-type 1 precursors to form $L e^{a}$ and $L e^{b}$, respectively, while the FUT2 (the Secretor enzyme) transfers fucose onto the terminal galactose on a type 1 precursor to form H-type 1. ${ }^{1,2}$ The FUT2 and FUT3 enzymes function independently and are controlled by the FUT2 and FUT3 Ioci, respectively. ${ }^{3,4}$ Individuals with a functional FUT3 enzyme will present with $L e^{a}$ or $L e^{b}$ depending on their FUT2 status, while a person with an inactivate FUT3 enzyme is considered as a Lewis-negative phenotype regardless of the FUT2 enzyme situation. In particular diseases, for example asthma ${ }^{5}$ and coronary heart disease ${ }^{6}$, the Lewis-negative phenotype as well as mutations of the FUT3 gene have been shown to be associated with an increased prevalence and risk of these diseases.

It has been well demonstrated that FUT3 enzyme activity is regulated by single nucleotide polymorphisms (SNPs) of the Lewis gene (FUT3). The mutations 202T>C ${ }^{7,8}$, $508 \mathrm{G}>\mathrm{A}^{3,9,10}$, and $1067 \mathrm{~T}>\mathrm{A}^{1}$ encode non-functional alleles of the FUT3 gene designated as $1 e^{202}, l e^{508}$, and $l e^{1067}$, respectively. Homozygous mutation of one of these alleles results in inactivation of catalytic domains of FUT3 enzyme and so leads to lack of enzyme activity to produce the Lewis antigen. In contrast, $59 \mathrm{~T}>\mathrm{G}^{3}$ or $314 \mathrm{C}>\mathrm{T}^{7,8}$ alone do not affect enzyme activity and so are designated as $L e^{59}$, and $L e^{314}$, respectively. However, a combination of mutation $59 T>G$ with any other SNP can lead to non-functional FUT3, and the pair of mutations 202T $>C$ and $314 \mathrm{C}>\mathrm{T}$ can also inactivate FUT3 enzyme. ${ }^{11}$
FUT3 polymorphisms play a major role in the appearance of Lewis-negative individuals. The frequencies of these polymorphisms vary by ethnic group: SNPs at 202T>C and 314C>T are common in Caucasians ${ }^{12-14}$, while $508 \mathrm{G}>\mathrm{A}$ is prominent in East Asians ${ }^{9,10,15}$ and $1067 \mathrm{~T}>\mathrm{A}$ is common in Southeast Asians ${ }^{1,16}$ and Brazilians. ${ }^{17}$ In Thailand, the ethnic groups, cultures, lifestyles, and local languages are distinct between the northern, northeastern, central, and southern parts of Thailand. Different distributions of Lewis phenotypes in Thai blood donors between central and southern regions has been reported ${ }^{18-21}$, however, genetic data on Lewis mutation individuals is very limited. To date, the only evidence of Lewis polymorphisms in Thais is from a study by Liu et al. ${ }^{16}$ However, the Liu study was based on a small sample with unclassified origins of the participants, which are limitations of their findings. Hence, to provide more detailed assessment of FUT3 polymorphisms in a Thai population, the present study aimed to examine the prevalence of FUT3 polymorphisms of the five most common SNPs by PCR-SSP ${ }^{22,23}$ in the southern Thai population. A large cohort of Thai blood donors in the southern peninsular region of Thailand was recruited for the study. In addition, the impact of each SNP on the presence or absence of Lewis antigens on red blood cells was also investigated.

\section{Material and Methods}

The peripheral venous blood from leftover specimens was collected in ethylenediamine tetraacetic acid (EDTA) and screened for absence of infectious markers, according to Thailand blood collection guidelines. Blood donor application forms were screened, and donors from the southern region of Thailand were included and others excluded. Of the total 364 blood donors who met this criterion, 77 samples had been collected from the Blood Bank Unit, Songklanagarind Hospital, Songkhla province, and 287 samples from the Regional Blood Centre XII Songkhla, Thailand. 
The use of leftover specimens was approved by the Human Research Ethic Committee of the Faculty of Medicine, Prince of Songkla University (REC. 60-225-19-2).

Genomic deoxyribonucleic acid (gDNA) of the 364 blood samples was extracted from the buffy coat as described elsewhere. ${ }^{24}$ Briefly, with minor modifications, 6 $\mathrm{ml}$ of whole blood was centrifuged at $1,000 \times \mathrm{g}$ for $5 \mathrm{~min}$ and $300 \mu \mathrm{l}$ of the buffy coat was transferred into a fresh $12 \times 75 \mathrm{~mm}$ glass tube. The red blood cells (RBCs) were then lysed with $3 \mathrm{ml}$ of RBC lysis buffer (10 mM Tris- $\mathrm{HCl}$, $\mathrm{pH}$ 7.6, $10 \mathrm{mM} \mathrm{NaCl}, 5 \mathrm{mM} \mathrm{MgCl}{ }_{2}$ ), mixed and centrifuged at $1,000 \times \mathrm{g}$ for $10 \mathrm{~min}$ and the supernatant discarded. After the lysis step was performed three times, the pellet was re-suspended in $1 \mathrm{ml} \mathrm{RBC}$ lysis buffer and transferred to a new microcentrifuge tube. After centrifugation at 2,400×g for $2 \mathrm{~min}$, the supernatant was removed. Then $12 \mu \mathrm{l}$ of proteinase $\mathrm{K}, 300 \mu \mathrm{l}$ of $\mathrm{ddH}_{2} \mathrm{O}, 105 \mu \mathrm{l}$ of $10.0 \%$ SDS and $105 \mu \mathrm{l}$ of $7.5 \mathrm{M}$ Guanidine $\mathrm{HCl}$ were added and mixed, and the blend was incubated at $70{ }^{\circ} \mathrm{C}$ for $15 \mathrm{~min}$. After centrifugation at $9,580 \times \mathrm{g}$ for $10 \mathrm{~min}$, the supernatant was collected, followed by addition of $1 \mathrm{ml}$ of absolute ethanol and centrifugation. The supernatant was then discarded and the pellet was mixed with $469 \mu$ of $80.0 \%$ ethanol for $1 \mathrm{~min}$. After a final centrifugation at $9,580 \times \mathrm{g}$ for $5 \mathrm{~min}$, the supernatant was discarded. The DNA was then incubated at $70{ }^{\circ} \mathrm{C}$ until dry, and then dissolved in $100 \mu \mathrm{lof} \mathrm{ddH}_{2} \mathrm{O}$ and incubated at $70{ }^{\circ} \mathrm{C}$ for $5 \mathrm{~min}$. The DNA concentrations were measured by a NanoDrop Spectrophotometer (Thermo Scientific, USA) and kept at $-20{ }^{\circ} \mathrm{C}$ for Lewis genotyping by polymerase chain reaction amplification with sequencespecific primers (PCR-SSP).

Five common mutations of the Lewis gene (FUT3) were detected by PCR-SSP. The specific primers for the wild type and the mutations 59T>G, 202T>C, 314C>T, 508G >A, and 1067T>A were described previously. ${ }^{22}$ Human growth hormone (hGH) primers (forward-TGCCTTCCCAACCATTCCCTTA and reverse-
CCACTCACGGATTTCTGTTGTGTTTC) were used as internal controls. All oligonucleotide primers were synthesized by and purchased from Integrated DNA Technologies (Integrated DNA Technologies, Singapore). The twenty microliter PCR reaction mix comprised 12.6 $\mu \mathrm{l}$ of $\mathrm{ddH}_{2} \mathrm{O}, 4 \mu \mathrm{l}$ of $5 \mathrm{X}$ HOT FIREPol ${ }^{\circledR}$ Blend Master Mix (Solis BioDyne, Tartu, Estonia), $0.5 \mu \mathrm{l}$ each of $10 \mu \mathrm{M}$ Lewis forward and reverse primers, $0.2 \mu \mathrm{l}$ each of $10 \mu \mathrm{M}$ hGH forward and reverse primers, and $2 \mu \mathrm{l}$ of DNA template.

To amplify the SNPs 59T>G, 314C>T, 1067T>A and their wild types, PCR amplification was performed using a thermal cycler (Eppendorf Certificate, Germany), starting with initial activation at $95{ }^{\circ} \mathrm{C}$ for $15 \mathrm{~min}$ followed by 30 cycles of denaturation at $95{ }^{\circ} \mathrm{C}$ for $30 \mathrm{~s}$, annealing at $64{ }^{\circ} \mathrm{C}$ for $30 \mathrm{~s}$, and elongation at $72{ }^{\circ} \mathrm{C}$ for $45 \mathrm{~s}$, and a final elongation at $72{ }^{\circ} \mathrm{C}$ for $5 \mathrm{~min}$. Amplifications of SNPs at $202 T>C, 508 \mathrm{G}>\mathrm{A}$, and their wild types were run similarly, except for the annealing step being at $60{ }^{\circ} \mathrm{C}$ for 30 s. The PCR products were analyzed by $2.0 \%$ agarose gel electrophoresis using $1 \mathrm{X}$ Tris-Acetate-EDTA (TAE) buffer and visualized under a UV transilluminator (UVTEC Cambridge, USA).

Detection of the Lewis antigens on red blood cells was done by hemagglutination using a standard tube test. One hundred fifty-nine blood samples were randomly selected for serological testing. Red blood cells from these samples were washed in normal saline and prepared for a 3.0-5.0\% cell suspension. Murine monoclonal anti-Le $e^{a}$ and anti-Le ${ }^{b}$ antibodies specific to $\mathrm{Le}^{\mathrm{a}}$ and $L \mathrm{e}^{\mathrm{b}}$, respectively, (Epiclone ${ }^{\mathrm{m}}$, Immulab Pty Ltd., Australia) were used and the testing performed following the manufacturer's recommendations. Briefly, 1 drop of anti-Le $e^{a}$ or anti-Le $e^{b}$ was used, followed by addition of 1 drop of the cell suspension, and incubation at room temperature for $20 \mathrm{~min}$. Agglutination of the red blood cells was examined by the naked eyes after centrifugation at $500 \times \mathrm{g}$ for $30 \mathrm{~s}$ for anti-Le $\mathrm{e}^{\mathrm{a}}$ and centrifugation at 1,000 $\times g$ for $10 \mathrm{~s}$ for anti-Le $e^{b}$. The strength of the reaction was 
graded as 4+, 3+, 2+,1+, weak (positive under microscope), or negative according to the standard method.

The SNP frequencies of the five common mutations were analyzed using Microsoft Excel. Statistical analysis used the SPSS 16.0 program. Relationships between FUT3 polymorphisms and red cell phenotypes were analyzed by the chi-square test. The significance level was set at 0.05 .

\section{Results}

Frequencies of FUT3 SNPs and polymorphisms in Southern Thai blood donors

Overall, the frequency of the 59T>G mutation was $32.0 \%$, detected in 47 individuals (12.9\%) with homozygous mutation $(\mathrm{G} / \mathrm{G})$ and 139 individuals $(38.2 \%)$ with heterozygous mutation $(T / G)$. A polymorphism at the 202T>C mutation was the most common with a frequency of $46.6 \%$, while 12 individuals (3.3\%) were homozygous (C/C) and 315 individuals (86.5\%) were heterozygous (T/C). The frequency of SNP 314C>T was $21.7 \%$, detected in 5 individuals (1.4\%) as homozygous (C/C) and in 148 (40.7\%) as heterozygous $(\mathrm{C} / \mathrm{T})$ mutations. The frequency of SNP $508 \mathrm{G}>\mathrm{A}$ was $37.9 \%$, detected in 2 individuals $(0.6 \%)$ as homozygous (A/A) and in $272(74.7 \%)$ as heterozygous (G/A) mutations. The frequency of SNP 1067T>A was $25.0 \%$, detected in $24(6.6 \%)$ and 134 (36.9\%) individuals as homozygous (A/A) and heterozygous (T/A) mutations, respectively (Figure 1 ).

\section{Percentages (\%)}

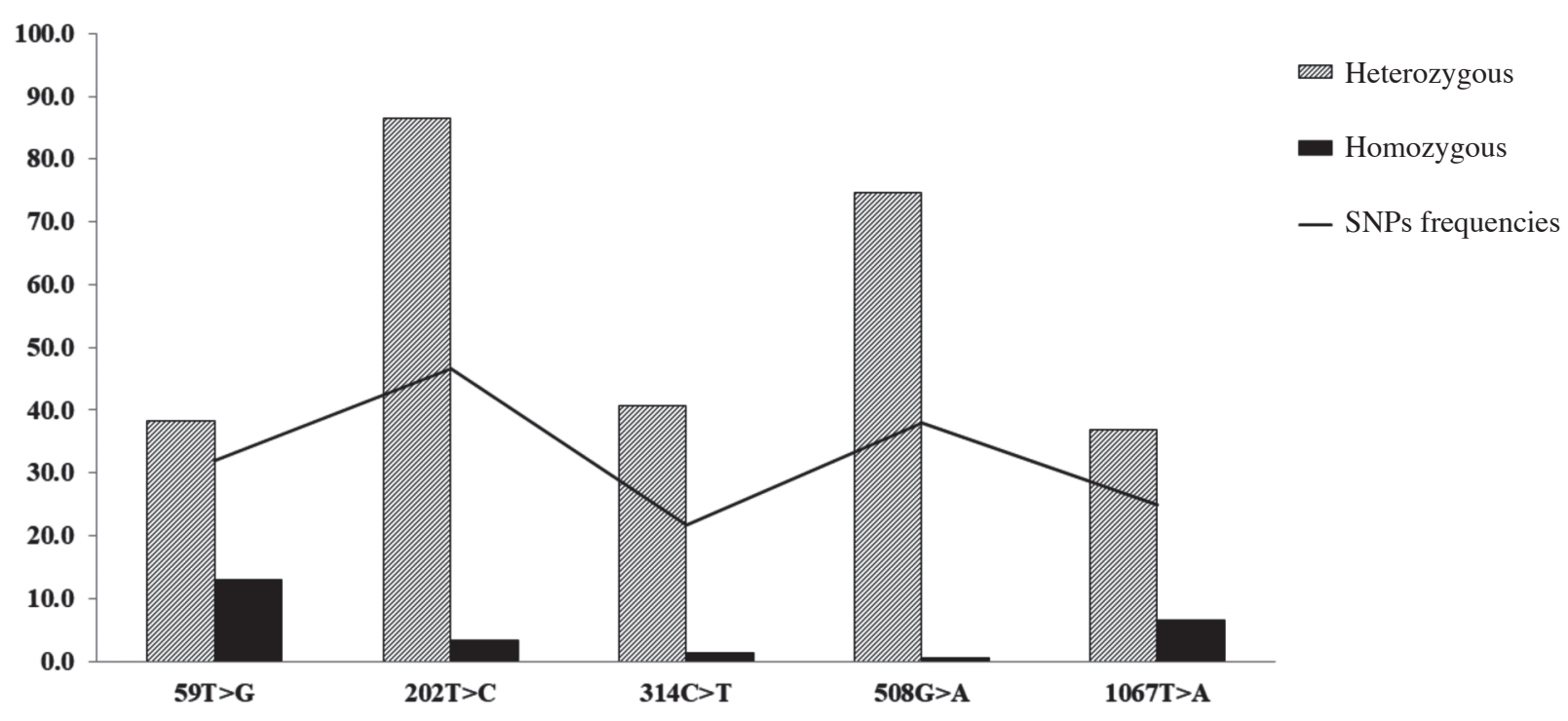

\section{Single nucleotide polymorphisms (SNPs)}

Figure 1 Frequencies of SNPs in the FUT3 gene in Thai blood donors as detected by PCR-SSP at 59T>G, 202T>C, 314C > T, 508G>A, and 1067T>A are indicated as black lines. Individuals with heterozygous mutations are indicated by gray bars, individuals with homozygous mutations are indicated by black bars $(n=364)$. 
Distribution of Lewis haplotypes and genotypes in Southern Thai blood donors

A single mutation or multiple mutations of particular SNPs can alter activity of the FUT3 enzyme. Wild-type $(L e)$, mutated 59T>G $\left(L e^{59}\right)$, and $314 \mathrm{C}>\mathrm{T}\left(L e^{314}\right)$ alleles do not affect this enzyme activity and are considered functional alleles. In this study, the wild-type Le allele was the most common functional allele, with an allele frequency of 0.420 , followed by 0.038 for the $L e^{59}$ and 0.010 for the $L e^{314}$ alleles (Table 1).

Furthermore, possible non-functionality was predicted for 24 FUT3 SNP combinations. It has been reported that SNP 202T>C and 314C>T are commonly on the same allele, whereas SNP 59T>G, 508G $>A$ and $1067 \mathrm{~T}>\mathrm{A}$ are on another allele. ${ }^{8,11}$ However, SNP 202T>C has been found in the same allele with mutations $59 T>G, 508 G>A$ or $1067 \mathrm{~T}>\mathrm{A}$, designated as the $1 e^{59,202,508,1067}$ allele, and was the most common in our cohort with an allele frequency of 0.073 (Table 1). In addition, co-existence of SNP 314C>T with other SNPs on the same allele was observed with an allele frequency of 0.066 for $1 e^{59,202,314,508,1067}$ (Table 1).

\section{Correlation of Lewis genotype and phenotype}

One hundred fifty-nine blood samples were randomly selected and assayed for the presence or absence of Lewis antigens on the red blood cells by serological phenotyping. Among these, the samples of 127 individuals (79.9\%) tested positive for anti-Lewis antibodies and were classified as Lewis-positive. This included 97 individuals (61.0\%) testing positive for $\mathrm{Le}(\mathrm{a}-\mathrm{b}+), 12$ individuals $(7.6 \%)$ for $\mathrm{Le}(\mathrm{a}+\mathrm{b}-)$, and 18 individuals $(11.3 \%)$ for Le $(a+b+)$ phenotypes. A non-agglutination reaction was observed in 32 individuals (20.1\%) and these were classified as Lewis-negative, or the Le(a-b-) phenotype.
Table 1 Frequencies of FUT3 SNP combinations in Thai blood donors from the southern Thailand $(n=364)$

\begin{tabular}{|c|c|c|c|}
\hline Number & SNP combination & $2 n=728$ & Frequency \\
\hline & Functional alleles & & \\
\hline & Total & 341 & 0.468 \\
\hline 1 & Le & 306 & 0.420 \\
\hline 2 & $L e^{59}$ & 28 & 0.038 \\
\hline \multirow[t]{3}{*}{3} & $L e^{314}$ & 7 & 0.010 \\
\hline & Non-functional all & & \\
\hline & Total & 387 & 0.532 \\
\hline 4 & $1 e^{59,202,508,1067}$ & 53 & 0.073 \\
\hline 5 & $1 e^{59,202,314,508,1067}$ & 48 & 0.066 \\
\hline 6 & $1 e^{59,202,508}$ & 42 & 0.058 \\
\hline 7 & $1 e^{202,314,508}$ & 40 & 0.055 \\
\hline 8 & $1 e^{202,508}$ & 38 & 0.052 \\
\hline 9 & $1 e^{202}$ & 31 & 0.043 \\
\hline 10 & $1 e^{59,202,314,508}$ & 26 & 0.036 \\
\hline 11 & $1 e^{59,1067}$ & 21 & 0.029 \\
\hline 12 & $1 e^{59,202,1067}$ & 21 & 0.029 \\
\hline 13 & $1 e^{202,314}$ & 11 & 0.015 \\
\hline 14 & $1 e^{1067}$ & 10 & 0.014 \\
\hline 15 & $l e^{202,314,508,1067}$ & 10 & 0.014 \\
\hline 16 & $1 e^{59,202,314,1067}$ & 10 & 0.014 \\
\hline 17 & $1 e^{59,508}$ & 6 & 0.008 \\
\hline 18 & $1 e^{508}$ & 5 & 0.007 \\
\hline 19 & $1 e^{202,508,1067}$ & 4 & 0.005 \\
\hline 20 & $1 e^{59,202}$ & 3 & 0.004 \\
\hline 21 & $1 e^{314,508}$ & 2 & 0.003 \\
\hline 22 & $1 e^{202,314,1067}$ & 1 & 0.001 \\
\hline 23 & $1 e^{314,1067}$ & 1 & 0.001 \\
\hline 24 & $1 e^{508,1067}$ & 1 & 0.001 \\
\hline 25 & $1 e^{59,202,314}$ & 1 & 0.001 \\
\hline 26 & $1 e^{59,314,1067}$ & 1 & 0.001 \\
\hline 27 & $1 e^{59,508,1067}$ & 1 & 0.001 \\
\hline
\end{tabular}

SNP=single nucleotide polymorphism

Of the Lewis-positive individuals, 7.1\% (9/127) were of the homozygous Le Le genotype, 80.3\% (102/127) were heterozygous Le/e, $0.8 \%$ (1/127) were Le $L e^{314}, 3.9 \%$ (5/127) Le $e^{59} / e$ genotype, and $3.1 \%$ (4/127) the $L e^{314} / e$ genotype. However, genotype and phenotype discordance was observed in 6/127 individuals (4.7\%) harboring a non-functional genotype. Of the 6 individuals, 4 were homozygous $1 e^{202} 1 e^{202}$ and 2 homozygous $1 e^{1067} 1 e^{1067}$. 
In the Lewis-negative phenotype group, 31.3\% $(10 / 32)$ carried the homozygous genotype of $1 e^{59,1067} /$ $1 e^{59,1067}$ with or without combination with other SNPs, while discordance between the Lewis genotype and Lewis phenotype was observed in $68.8 \%(22 / 32)$. Of these 22 individuals, $46.9 \%(15 / 32)$ carried the Le/e genotype, $18.8 \%(6 / 32)$ the $L e^{59} / e$ genotype, and $3.1 \%$ (1/32) the $L e^{314} \wedge$ genotype. The discrepancies between a positive phenotype carrying non-functional alleles of the FUT3 gene and a negative phenotype carrying functional alleles will be discussed later. However, Fisher's exact test indicated an association between the Lewis genotype and the phenotype (Fisher's exact test=15.725, p-value $<0.001$ ).

We also examined the associations between each SNP and the presence or absence of Lewis antigens using the chi-square test, and found that more Lewis-negative individuals carried the homozygous mutations 59T>G (76.2\% vs $\left.23.8 \%, \chi^{2}=49.873, d f=2, p-v a l u e<0.001\right)$ and $1067 \mathrm{~T}>\mathrm{A} \quad\left(83.3 \%\right.$ vs $16.7 \%, \chi^{2}=44.520, \mathrm{df}=2, \mathrm{p}$-value $<$ 0.001) than Lewis-positive individuals. In contrast, an SNP at position 202T>C was found more often in Lewis-positive individuals than in Lewis-negative individuals (Fisher's exact

Table 2 Proportions of phenotypes and FUT3 gene SNPs 59T>G, 202T>C, 314C>T, 508G>A, and 1067T>A in Lewispositive and Lewis-negative Thai blood donors from the southern Thailand $(n=159)$

\begin{tabular}{|c|c|c|c|c|c|c|c|}
\hline \multirow{2}{*}{ SNPs } & \multicolumn{2}{|c|}{$\begin{array}{l}\text { Lewis-positive phenotype } \\
\qquad(n=127)\end{array}$} & \multicolumn{2}{|c|}{$\begin{array}{l}\text { Lewis-negative phenotype } \\
\qquad(\mathrm{n}=32)\end{array}$} & \multirow{2}{*}{$\chi^{2}$} & \multirow{2}{*}{ df } & \multirow{2}{*}{$p$-value } \\
\hline & Count (n) & $\begin{array}{l}\text { Expected } \\
\text { count }(\%)\end{array}$ & Count (n) & $\begin{array}{l}\text { Expected } \\
\text { count }(\%)\end{array}$ & & & \\
\hline Genotype & & & & & $15.725^{a}$ & 1 & $<0.001$ \\
\hline Le Le, Le le & 121 & 84.6 & $22^{b}$ & 15.4 & & & \\
\hline le/e & $6^{c}$ & 37.5 & 10 & 62.5 & & & \\
\hline $59 \mathrm{~T}>\mathrm{G}$ & & & & & 49.873 & 2 & $<0.001$ \\
\hline$T / T$ & 63 & 94.0 & 4 & 6.0 & & & \\
\hline$T / G$ & 59 & 83.1 & 12 & 16.9 & & & \\
\hline$G / G$ & 5 & 23.8 & 16 & 76.2 & & & \\
\hline $202 T>C$ & & & & & $9.408^{a}$ & 2 & 0.009 \\
\hline$T / T$ & 26 & 96.3 & 1 & 3.7 & & & \\
\hline$T / C$ & 97 & 75.8 & 31 & 24.2 & & & \\
\hline$C / C$ & 4 & 100.0 & 0 & 0.0 & & & \\
\hline $314 C>T$ & & & & & $0.374^{a}$ & 2 & 0.829 \\
\hline$C / C$ & 71 & 81.6 & 16 & 18.4 & & & \\
\hline$C / T$ & 52 & 77.6 & 15 & 22.4 & & & \\
\hline$T / T$ & 4 & 80.0 & 1 & 20.0 & & & \\
\hline $508 \mathrm{G}>\mathrm{A}$ & & & & & $0.675^{a}$ & 1 & 0.411 \\
\hline$G / G$ & 28 & 84.8 & 5 & 15.2 & & & \\
\hline$G / A$ & 99 & 78.6 & 27 & 21.4 & & & \\
\hline $1067 \mathrm{~T}>\mathrm{A}$ & & & & & 44.520 & 2 & $<0.001$ \\
\hline$T / T$ & 84 & 94.4 & 5 & 5.6 & & & \\
\hline$T / A$ & 41 & 70.7 & 17 & 29.3 & & & \\
\hline$A / A$ & 2 & 16.7 & 10 & 83.3 & & & \\
\hline
\end{tabular}

aValues by Fisher's exact test

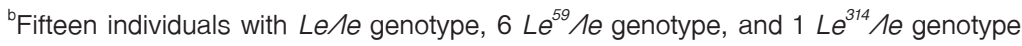

${ }^{c}$ Four individuals with homozygous $l e^{202} / e^{202}$, and 2 homozygous $l e^{1067} / e^{1067}$

SNPs=single nucleotide polymorphisms 
test $=9.408, p$-value=0.009). No association between the SNPs $314 \mathrm{C}>\mathrm{T}$ and $508 \mathrm{G}>\mathrm{A}$ and the Lewis phenotype was observed ( $p$-value $=0.829$, or $p$-value $=0.423$, respectively) (Table 2).

\section{Discussion}

Polymorphisms of the FUT3 gene have been identified in several populations and their prevalence found to be related to ethnicity. In this study we investigated the prevalence of the five common SNPs 59T>G, 202T>C, 314C>T, 508G $>A$, and 1067T>A in southern Thai blood donors. In contrast to a previous report from Thailand which found the mutation 1067T>A was the most frequent in their healthy Thai subjects ${ }^{16}$, the SNPs 202T>C and $508 \mathrm{G}>\mathrm{A}$ were the two most prevalent in our cohort. This suggests there may be variations in polymorphisms of the FUT3 gene in the Thai population related to ethnicity and genetic background. Although the SNPS 202T>C 7,8 and $508 \mathrm{G}>\mathrm{A}^{3,9,10}$ can inactivate fucosylation of the FUT3 enzyme leading to no production of Lewis antigens, these point mutations were not associated with the absence of Lewis antigens in Lewis-negative individuals in the present study. This can be explained by noting the presence of highly heterozygous mutations in our study group, perhaps leading to the masking of non-functional $/ e^{202}$ or $1 e^{508}$ alleles by the functional $L e, L e^{59}$, or $L e^{314}$ alleles when they are located together on homologous chromosomes.

The third and fourth most common SNPs observed in the present study were 59T>G and $1067 \mathrm{~T}>\mathrm{A}$. A mutation at $59 \mathrm{~T}>\mathrm{G}$ alone results in the functional allele $L e^{59}$ which has been commonly found in Caucasian Americans ${ }^{13}$ and the Brazilian population. ${ }^{17}$ SNP 59T>G, in conjunction with other SNPs such as $508 \mathrm{G}>\mathrm{A}$, results in a non-functional allele $1 e^{59,508}$ that has been commonly found in Lewisnegative Japanese ${ }^{3}$ and Africans. ${ }^{25}$ The non-functional allele $1 e^{59,1067}$ has been mainly found in Lewis-negative phenotype in Japanese ${ }^{3}$ and Indonesians ${ }^{1}$ and was seen also in our cohort. In addition, we found evidence of an association between the SNPs 59T>G and 1067T>A and the occurrence of the Lewis-negative phenotype, likely due to the high level of homozygosity in the overall Thai population. Even though the mutation 314C>T does not alter FUT3 enzyme activity, it is commonly co-localized with 202T>C because they are on the same allele, whereas the other SNPs are on another allele. $^{8}$ Although co-localization of $59 \mathrm{~T}>\mathrm{G}$, $508 \mathrm{G}>\mathrm{A}$, or $1067 \mathrm{~T}>\mathrm{A}$ on the same allele with $202 \mathrm{~T}>\mathrm{C}$ or $314 \mathrm{C}>\mathrm{T}$ is rare, combination of the $59 \mathrm{~T}>\mathrm{G}, 202 \mathrm{~T}>\mathrm{C}$, and 1067T>A mutations have been reported from Denmark ${ }^{11}$ and were present in this study as well (Table 1).

According to our serological study on the Lewis antigen on red blood cells, we found, similar to previous studies $^{2,16-18,26}$, that the Le(a-b+) phenotype was predominate over the other phenotypes in our study population. Besides a functional FUT3 gene, the $\mathrm{Le}^{\mathrm{b}}$ antigen requires a dual function FUT2 gene. The FUT2 enzyme is usually more active than the FUT3 enzyme, therefore, in Le(a-b+) individuals, the type I precursor is more rapidly converted into H-type I. Then the FUT3 enzyme consequently converts the $\mathrm{H}$-type 1 to form the $\mathrm{Le}^{\mathrm{b}}$ antigen. The present study found that $72.3 \%$ of the donors (115 out of 159 ), had $\mathrm{Le}^{\mathrm{b}}$ alone or both the $\mathrm{Le}^{\mathrm{a}}$ and $\mathrm{Le}^{\mathrm{b}}$ antigens, suggesting secretor status, while $7.6 \%$ of the donors (12 out of 159) were non-secretors as they were typed as the Le(a+b-) phenotype, so they had only the $\mathrm{Le}^{\mathrm{a}}$ antigen.

However, in some secretor individuals, the FUT2 enzyme is only weakly active, leaving a portion of the type I precursor for the FUT3 enzymes to produce Le $\mathrm{a}^{\mathrm{a}}$, and so present the $\mathrm{Le}(\mathrm{a}+\mathrm{b}+)$ phenotype. ${ }^{4,27}$ This phenotype is very rare in Caucasians, but is relatively common in Asians; for example studies have found rates in Malays, Chinese, and Japanese ranging from $7.0-33.0 \%^{2,28,29}$, and the $11.3 \%$ individuals observed in this study. This finding in our study is, however, in contrast to previous studies from Thailand ${ }^{19,20}$ in which the $L e(a+b+)$ phenotype was not found in central 
Thailand participants. However, molecular analysis of FUT2 gene mutations may provide data to explain the weak secretor status in our southern Thailand population.

In terms of the discordance between the Lewis phenotype and genotype in the present study, 6 of the Lewis-positive phenotypes were carrying le/e nonfunctional genes. This finding suggests that the Lewis antigen found in those individuals might have been synthesized by other fucosyltransferase enzymes. FUT5 has been shown to catalyze the fucosylation of the $\alpha 1,4$ position on the type I precursor and $\mathrm{H}$-type 1 acceptor to produce $\mathrm{Le}^{\mathrm{a}}$ and $\mathrm{Le}^{\mathrm{b}}$ antigens, respectively. ${ }^{11,30}$

The Lewis-negative phenotype (Le(a-b-)) has been reported at $17.5 \%$ and $31.0 \%$ in previous studies on the Thai population $^{16,18}$, and accounted for $20.1 \%$ (32 out of 159) in this study. The Le(a-b-) phenotype is classified into two subgroups: i) the genuine Lewis-negative characterized by the absence of Lewis antigens in the blood and saliva, and the presence of homozygous le/e alleles, and ii) the non-genuine Lewis-negative, characterized by the absence of Lewis antigens in the blood, but the presence of Lewis antigens in the saliva, and the presence of heterozygous Le/e alleles. ${ }^{17}$

In the present study, amongst the Le(a-b-) phenotype, 10 out of 32 individuals carried homozygous $1 e^{59,1067} 1 e^{59,1067}$ alleles, with or without combinations of other SNPs, suggesting that $l e^{59,1067}$ has considerable responsibility for regulation of the Lewis-negative phenotype in our population. This finding is consistent with previous studies which found that SNP 1067T>A was commonly found in Lewis-negative individuals in Southeast Asians including Thais working in Taiwan, Filipinos, and Indonesians. ${ }^{1,16}$ Another previous study ${ }^{17}$ postulated that these individuals could be genuine Lewis-negative phenotypes.

However, 22 out of the 32 Lewis-negative individuals in our study carried heterozygous Le he alleles. It is likely that such individuals may synthesize and present small amounts of Lewis antigen in their secretions, but may not be adsorbed onto red blood cell surfaces, giving a nongenuine Lewis-negative phenotype. ${ }^{17}$ Unfortunately, it was not possible to include secretion tests in this current study, so no secretion data were available for analysis. This hypothesis will require further molecular analysis of FUT2 mutations in order to provide more information of secretor status of such non-genuine Lewis-negative individuals.

\section{Conclusion}

In summary, this report provides molecular evidence of FUT3 polymorphisms in the southern Thai population. The results show statistical consistency between the PCRSSP analysis and the serological investigations. The SNPS $202 T>C$ and $508 G>A$ were the most prevalent in this study, but were not associated with the Lewis-negative phenotype due to the high frequency of heterozygous individuals. The 59T>G and 1067T>A SNPs were mostly expressed in the homozygous form, and their combination mutation suggests that $l e^{59,1067}$ is largely responsible for the Lewisnegative phenotype in our southern Thai population. Hence, molecular analysis of FUT3 polymorphisms is useful for identification of molecular markers associated with ethnicity. In addition to phenotyping, an investigation of genetic FUT3 polymorphisms may help understand the role(s) of the Lewis blood group in infections or other clinical diseases.

\section{Acknowledgement}

This project was funded by a Prince of Songkla University research grant, number MET6202076S, and a Faculty of Medical Technology research grant, number MET601523S. The authors also acknowledge Assoc. Prof. Seppo Karrila and the Research and Development Office, Prince of Songkla University, for English editing of the manuscript. 


\section{Conflict of interest}

The authors have no conflicts of interest.

\section{References}

1. Mollicone R, Reguigne I, Kelly RJ, Fletcher A, Watt J, Chatfield $S$, et al. Molecular basis for Lewis alpha(1,3/1,4)-fucosyltransferase gene deficiency (FUT3) found in Lewis-negative Indonesian pedigrees. J Biol Chem 1994;269:20987-94.

2. Chang JG, Yang TY, Liu TC, Lin TP, Hu CJ, Kao MC, et al Molecular analysis of secretor type alpha(1,2)-fucosyltransferase gene mutations in the Chinese and Thai populations. Transfusion 1999;39:1013-7.

3. Nishihara S, Narimatsu H, Iwasaki H, Yazawa S, Akamatsu S, Ando $\mathrm{T}$, et al. Molecular genetic analysis of the human Lewis histo-blood group system. J Biol Chem 1994;269:29271-8.

4. Koda Y, Soejima M, Liu Y, Kimura H. Molecular basis for secretor type alpha(1,2)-fucosyltransferase gene deficiency in a Japanese population: a fusion gene generated by unequal crossover responsible for the enzyme deficiency. Am J Hum Genet 1996;59:343-50.

5. Kauffmann F, Frette C, Pham QT, Nafissi S, Bertrand JP, Oriol R. Associations of blood group-related antigens to FEV1, wheezing, and asthma. Am J Respir Crit Care Med 1996;153: 76-82.

6. Salomaa V, Pankow J, Heiss G, Cakir B, Eckfeldt JH, Ellison $\mathrm{RC}$, et al. Genetic background of Lewis negative blood group phenotype and its association with atherosclerotic disease in the NHLBI family heart study. J Intern Med 2000;247:689-98.

7. Elmgren A, Börjeson C, Svensson L, Rydberg L, Larson G. DNA sequencing and screening for point mutations in the human Lewis (FUT3) gene enables molecular genotyping of the human Lewis blood group system. Vox Sang 1996;70:97-103.

8. Elmgren A, Mollicone R, Costache M, Börjeson C, Oriol R, Harrington $\mathrm{J}$, et al. Significance of individual point mutations, T202C and C314T, in the human Lewis (FUT3) gene for expression of Lewis antigens by the human alpha(1,3/1,4)fucosyltransferase, Fuc-TIII. J Biol Chem 1997;272:21994-8.

9. Koda Y, Kimura H, Mekada E. Analysis of Lewis fucosyltransferase genes from the human gastric mucosa of Lewispositive and -negative individuals. Blood 1993;82:2915-9.

10. Nishihara S, Yazawa S, Iwasaki H, Nakazato M, Kudo T, Ando T, et al. Alpha $(1,3 / 1,4)$ fucosyltransferase (FucT-III) gene is inactivated by a single amino acid substitution in Lewis histoblood type negative individuals. Biochem Biophys Res Commun 1993;196:624-31.

11. Orntoft TF, Vestergaard EM, Holmes E, Jakobsen JS, Grunnet N, Mortensen M, et al. Influence of Lewis alpha1-3/4-L-fucosyltransferase (FUT3) gene mutations on enzyme activity, erythrocyte phenotyping, and circulating tumor marker sialyl-Lewis a levels. J Biol Chem 1996;271:32260-8.

12. Serpa J, Almeida R, Oliveira C, Silva FS, Silva E, Reis C, et al. Lewis enzyme (alpha1-3/4 fucosyltransferase) polymorphisms do not explain the Lewis phenotype in the gastric mucosa of a Portuguese population. J Hum Genet 2003;48:183-9.

13. Cakir B, Pankow JS, Salomaa V, Couper D, Morris TL, Brantley $\mathrm{KR}$, et al. Distribution of Lewis (FUT3) genotype and allele: frequencies in a biethnic United States population. Ann Hematol 2002;81:558-65

14. Soejima M, Munkhtulga L, Iwamoto S, Koda Y. Genetic variation of FUT3 in Ghanaians, Caucasians, and Mongolians. Transfusion 2009;49:959-66.

15. Park HD, Park KU, Song J, Ki CS, Han KS, Kim JQ. The relationship between Lewis/Secretor genotypes and serum carbohydrate antigen 19-9 levels in a Korean population. Korean J Lab Med 2010;30:51-7.

16. Liu TC, Chang JG, Lin SF, Chang WC, Yang TY, Lin CL, et al. Lewis (FUT3) genotypes in Taiwanese, Thai, and Filipino populations. Ann Hematol 2000;79:599-603.

17. Corvelo TC, de Loiola Rdo S, Aguiar DC, de Matos Gde C, de Brito DC. The Lewis histo-blood group system: molecular analysis of the 59T>G, 508G $>A$, and 1067T>A polymorphisms in an Amazonian population. PLoS One 2013;8:e69908.

18. Ovataga P, Kerdkaewngam K, Mekchay S, Tubrod J, Chiewsilp $P$. Lewis blood group antigens on red blood cells and in saliva of Thai blood donors. J Hematol Transfus Med 2018;28:407-14.

19. Nathalang O, Kuvanont S, Punyaprasiddhi P, Tasaniyanonda C, Sriphaisal T. A preliminary study of the distribution of blood group systems in Thai blood donors determined by the gel test. Southeast Asian J Trop Med Public Health 2001;32:204-7.

20. Chandanayingyong $D$, Bejrachandra $S$, Metaseta $P$, Pongsataporn S. Further study of Rh, Kell, Duffy, P, MN, Lewis and Gerbiech blood groups of the Thais. Southeast Asian $J$ Trop Med Public Health 1979;10:209-11.

21. Buathong D, Hassarin S. Detection of clinically dignificant minor blood group antigens of blood donors in Songklanagarind Hospital. Songkla Med J 2016;34:109-18. 
22. Grahn A, Elmgren A, Aberg L, Svensson L, Jansson PA, Lönnroth $P$, et al. Determination of Lewis FUT3 gene mutations by PCR using sequence-specific primers enables efficient genotyping of clinical samples. Hum Mutat 2001;18:358-9.

23. Itoh $Y$, Satoh K, Takahashi K, Maeda K, Tokura T, Kobayashi R. Evaluation of Lewis genotyping by four PCR-based methods. Int Congr Ser 2006;1288:819-21.

24. Tomee Y, Chaiden J, Palacajornsuk P. Detection of Mia genotype of DNA extracted from blood and hair roots by Polymerase Chain Reaction. Bull Chiang Mai Assoc Sci 2009;42:242-50.

25. Pang H, Liu Y, Koda Y, Soejima M, Jia J, Schlaphoff T, et al. Five novel missense mutations of the Lewis gene (FUT3) in African (Xhosa) and Caucasian populations in South Africa. Hum Genet 1998;102:675-80.

26. Hong YJ, Hwang SM, Kim TS, Song EY, Park KU, Song J, et al. Significance of Lewis phenotyping using saliva and gastric tissue: comparison with the Lewis phenotype inferred from Lewis and secretor genotypes. Biomed Res Int 2014; 2014:573652.

27. Yu LC, Yang YH, Broadberry RE, Chen YH, Chan YS, Lin M. Correlation of a missense mutation in the human Secretor alpha 1,2-fucosyltransferase gene with the Lewis $(a+b+)$ phenotype: a potential molecular basis for the weak Secretor allele (Sew). Biochem J 1995;312:329-32.

28. Henry S, Oriol R, Samuelsson B. Lewis histo-blood group system and associated secretory phenotypes. Vox Sang 1995;69: 166-82.

29. Musa RH, Ahmed SA, Hashim H, Ayob Y, Asidin NH, Choo PY, et al. Red cell phenotyping of blood from donors at the National blood center of Malaysia. Asian J Transfus Sci 2012;6:3-9.

30. Dupuy F, Germot A, Marenda M, Oriol R, Blancher A, Julien R, et al. Alpha1,4-fucosyltransferase activity: a significant function in the primate lineage has appeared twice independently. Mol Biol Evol 2002;19:815-24. 